\section{IMPLEMENTATION OF ROAD SAFETY INTERVENTIONS IN LOW AND MIDDLE INCOME COUNTRIES - A CASE OF KENYA}

${ }^{1}$ Kunuz Abdella, ${ }^{1}$ Duncan Kibogong, ${ }^{2}$ Kidist Bartolomeos, ${ }^{3}$ Wilfred Mwai. ${ }^{1}$ World Health Organisation, Kenya; ${ }^{2}$ World Health Organisation, Geneva; ${ }^{3}$ Ministry of Health, Kenya

\subsection{6/injuryprev-2016-042156.903}

Background Kenya was one of 10 countries, and the only one in sub-Saharan Africa that participated in a 5-year road traffic injury prevention demonstration project, which was part of the Bloomberg Philanthropies Global Road Safety Programme (BPGRSP). The global programme focused on implementation of evidence based road safety interventions. In Kenya, the focus of the Project was to increase helmet wearing among motorcycle riders and to reduce speed on the main highways which pass through two implementation sites (sub-counties).

Methods Project was implemented between 2010-2014. Implementation of intervention was led by a consortium of six organisations. WHO as one of the organisations that took the role of coordination between national government and consortium partners. The local work was led by a local multi-agency working group of stakeholders (under the leadership of $\mathrm{MOH}$ ) which were responsible for developing, implementing and monitoring of national and/or local work plan. A core package of road safety interventions (social marketing, legislative review, training of journalists, trauma care improvement, data system strengthening, child pedestrian safety) targeting the identified risk factors, were developed and implemented. Interventions were adapted for the local setting. Monitoring and evaluation, capacity development on enforcement and engagement with NGOS was led by the other consortium partners.

Results In the 5 years of the project, several achievements in most of the intervention areas were observed. Speed compliance at both intervention sites reached above 90\%. Helmet wearing improved slightly (by 26\%), but only at one site. There was a significant decline (over $85 \%$ ) in the number of child pedestrian injuries and deaths at pilot sites. The national helmet standard was revised. Efforts to integrate some of the activities into the National Transportation Safety Authority and MOH's work is ongoing.

Conclusions Targeted multi-sectoral action using a combination of evidence-based interventions implemented as a package, with adaptation to the local setting and capacity can lead to positive outcome. The sustainability of the positive results at intervention sites and scale up of the proven interventions to national level is a challenge in Low and middle income countries.

\section{Child and Adolescent Safety}

\section{Post Wed 3.2}

\section{ACTIVE SCHOOL TRANSPORTATION AND STROLLER USE IN KINDERGARTEN CHILDREN IN TORONTO, CANADA}

1,2Linda Rothman, ${ }^{1}$ Alison Macpherson, ${ }^{2}$ Andrew Howard, ${ }^{2}$ Patricia Parkin, 1,25arah A Richmond, ${ }^{2}$ Catherine S Birken. ${ }^{1}$ York University, Toronto, Canada; ${ }^{2}$ Hospital for Sick Children Toronto, Canada

\subsection{6/injuryprev-2016-042156.904}

Background Declines in child pedestrian motor vehicle collisions have occurred over the past 20 years possibly due to the simulaneous decline in children walking to school. Active school transportation (AST) is a form of physical activity that should be encouraged as all children make the daily school commute. Little is known about AST in kindergarten students (4-5 years). Young children may travel to school by sedentary means such as by car, stroller or wagon, due to parental concerns regarding traffic safety; however, recent recommendations by several professional associations have discouraged stroller use due to concerns their use may lead to reduced physical activity.

Methods School transportation modes for kindergarten students were compared to those of students of all ages. Observational transportation mode counts were conducted in two samples in May-June 2015 at kindergarten-grade 6 schools in Toronto, Canada: 1) outside of schools with separate kindergarten entrances ( $\mathrm{n}=26$ schools); 2 ) at optimal viewing locations for all-age students $(n=100$ schools). Proportions of children arriving by different modes were compared between samples using Chi-square statistics.

Results The use of active modes was significantly lower in the kindergarten sample ( $\mathrm{n}=26$ schools) compared to those in the all-age sample ( $\mathrm{n}=100$ schools); 60\% versus 74\%, Chi-square $=91.37, \mathrm{p}<0.001$. The predominant sedentary travel mode was by car $(38 \%)$. The proportion of kindergarten children arriving by stroller or wagons was $1.8 \%$.

Conclusions Strollers and wagons were not generally used for school travel by kindergarten students. Observed AST was significantly lower in kindergarten students compared to all ages. The overuse of cars for school travel for young children requires further examination to reduce sedentary behaviour and to decrease vehicle traffic around schools which puts all child pedestrians at increased risk for injury.

\section{DISTRACTED WALKING AMONG TEENS AND PRE-TEENS IN U.S. AND CHINA: ANALYSIS OF OBSERVATIONS}

${ }^{1}$ Priti Gautam, ${ }^{2}$ Monica Cui, ${ }^{2}$ Fannie Wang, ${ }^{1}$ Kristin Rosenthal, ${ }^{1}$ Rennie Ferguson. ' Safe Kids Worldwide (USA); ${ }^{2}$ Safe Kids China

\subsection{6/injuryprev-2016-042156.905}

Background To determine the level of distracted walking among teenagers and pre-teens in the U.S. and China, research examined the percentage of teenagers and pre-teens crossing the street near schools while distracted in a sample of communities in both nations. Results and focus group findings were used to develop targeted interventions.

Methods Observations were made of 34,325 of teens and preteens crossing streets near schools in 24 communities in the U.S, and 8,250 observations were made of teens and preteens in 8 communities in China. Data was collected near middle schools and high schools. Observers conducted two morning and afternoon sessions, on different days but held at the same time, on school days in good weather. Each observer focused on one crossing location. Students also participated in focus groups that explored attitudes and perceived risks.

Results Most frequent forms of distraction in the U.S. were texting, 39\%, headphone use, 39\%, and talking on phones, $20 \%$. In China, key distractions were headphones, $42.5 \%$, texting, $22.5 \%$, and games, $15.8 \%$. The odds of a girl crossing the street distracted were greater than of a boy in both countries. Differences in distraction levels were also observed when traffic lights are present and at different times of the day. During focus groups in both nations, nearly $50 \%$ of students reported cell phone use 